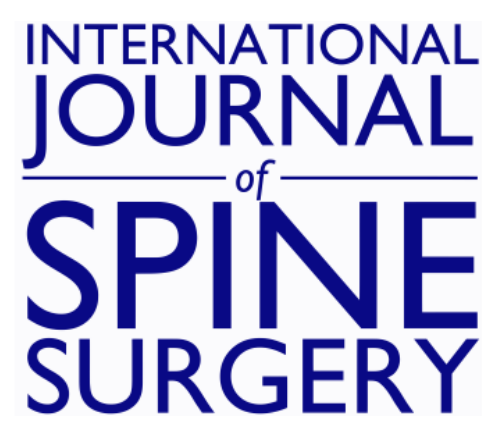

\title{
Preservation of Spine Motion in the Surgical Treatment of Adolescent Idiopathic Scoliosis Using an Innovative Apical Fusion Technique: A 2-Year Follow-Up Pilot Study
}

POORIA HOSSEINI, ALLEN CARL, MICHAEL GREVITT, COLIN NNADI, MARTIN REPKO, DENNIS G. CRANDALL, UFUK AYDINLI, LUBOS REHÁK, MARTIN ZABKA, STEVEN SEME and BEHROOZ A. AKBARNIA

Int J Spine Surg 2018, 12 (4) 441-452

doi: https://doi.org/10.14444/5053

http://ijssurgery.com/content/12/4/441

This information is current as of April 26, 2023.

Email Alerts Receive free email-alerts when new articles cite this article. Sign up at: http://ijssurgery.com/alerts 


\title{
Preservation of Spine Motion in the Surgical Treatment of Adolescent Idiopathic Scoliosis Using an Innovative Apical Fusion Technique: A 2-Year Follow-Up Pilot Study
}

\author{
POORIA HOSSEINI, MD,${ }^{1}$ ALLEN CARL, MD,${ }^{2}$ MICHAEL GREVITT, $\mathrm{MD},{ }^{3}$ COLIN NNADI, MD,${ }^{4}$ MARTIN \\ REPKO, MD, ${ }^{5}$ DENNIS G. CRANDALL, MD ${ }^{6}$ UFUK AYDINLI, MD,${ }^{7}$ ĽUBOŠ REHÁK, MD, PhD ${ }^{8}$ \\ MARTIN ZABKA, MD, ${ }^{9}$ STEVEN SEME, MS, ${ }^{10}$ BEHROOZ A. AKBARNIA, MD ${ }^{1}$ \\ ${ }^{I}$ San Diego Spine Foundation, San Diego, California, ${ }^{2}$ Albany Medical Center, Albany, New York, ${ }^{3}$ Nottingham University Queens Medical Centre, Nottingham \\ UK, ${ }^{4}$ Nuffield Orthopaedic Centre, Oxford University Hospital, Headington, Oxford, UK, ${ }^{5}$ University Hospital Brno, Orthopaedic Department Faculty, Brno, \\ Czech Republic, ${ }^{6}$ Sonoran Spine Center, Tempe, Arizona, ${ }^{7}$ Medicabil Hospital, Nilufer, Bursa, Turkey, ${ }^{8}$ Comenius University, Bratislava, Slovakia, ${ }^{9}$ Department \\ of Orthopaedics and Traumatology, University Hospital Bratislava, Ruzinovska, Bratislava, Slovakia, ${ }^{10}$ Seme Device Consulting, Savage, Minnesota
}

\begin{abstract}
Background: This trial reports the 2-year and immediate postremoval clinical outcomes of a novel posterior apical short-segment (PASS) correction technique allowing for correction and stabilization of adolescent idiopathic scoliosis (AIS) with limited fusion.

Methods: Twenty-one consecutive female AIS patients were treated at 4 institutions with this novel technique. Arthrodesis was limited to the short apical curve after correction with translational and derotational forces applied to upper and lower instrumented levels. Instrumentation spanned fused and unfused segments with motion and flexibility of unfused segments maintained. The long concave rods were removed at maturity. Radiographic data collected included preoperative and postoperative data for up to 2 years as well as after long rod removal.

Results: All 21 patients are beyond 2 years postsurgery. Average age at surgery was 14.2 years (11-17 years). A mean of $10.5 \pm 1$ levels per patient were stabilized and $5.0 \pm 0.5$ levels $(48 \%)$ were fused. Cobb angle improved from $56.1^{\circ} \pm 8.0^{\circ}$ to $20.8^{\circ} \pm 7.8^{\circ}\left(62.2^{\circ}\right.$ improvement $)$ at 1 year and $20.9^{\circ} \pm 8.4^{\circ},\left(62.0^{\circ}\right.$ improvement $)$ at 2 years postsurgery. In levels instrumented but not fused, motion was $26^{\circ} \pm 6^{\circ}$ preoperatively compared to $10^{\circ} \pm 4^{\circ}$ at 1 year postsurgery, demonstrating $38 \%$ maintenance of mobility in nonfused segments. There was no report of implant-related complications.
\end{abstract}

Conclusions: PASS correction technique corrected the deformity profile in AIS patients with a lower implant density while sparing $52 \%$ of the instrumented levels from fusion through the 2-year follow-up.

New Technology

Keywords: adolescent idiopathic scoliosis, short apical fusion, motion preservation

\section{INTRODUCTION}

Common techniques for correction of adolescent idiopathic scoliosis (AIS) involve posterior arthrodesis of all motion segments that are instrumented, including the curve apex and several segments both proximal and distal to the apex in order to control the curve and optimize the correction. Constructs usually consist of vertically attached rigid rod-screw connections with a high density of pedicle screws, typically realigned with a combination of derotational and translational techniques. ${ }^{1-13}$ Although effective at correcting the deformity, this treatment immobilizes the entire length of the spine spanned by the instrumentation to assist with promoting fusion, resulting in permanent loss of motion of all instrumented levels. Long fusions carry the potential of earlier adjacent segment degeneration, instability, discomfort, or pain. ${ }^{14,15}$ These clinical observations have prompted investigation of newer, less aggressive methods that could achieve similar or better outcomes. ${ }^{16}$ In addition, cost and safety concerns, as well as other factors, have prompted considerations of lower implant-density constructs. $^{17,18}$

The safety, efficacy, and motion preservation of this novel technique has already been reported through a 1-year follow-up. ${ }^{1}$ The purpose of this clinical pilot trial is to report 2-year performance and safety data for this new posterior instrumentation system for the surgical treatment of AIS. The surgical treatment under study addresses 4 basic 
Table 1. Summary of key inclusion and exclusion criteria.

Inclusion Criteria

Lenke type $1 \mathrm{~A}$ or $1 \mathrm{~B}$

Main thoracic curve $40^{\circ}-65^{\circ}$

Flexibility $>40 \%$

Sanders stage $3-7$

Body mass index $\leq 30$

Exclusion Criteria

History of metabolic disease

Thoracic hyperkyphosis $>50^{\circ}$

Previous spine surgery

Allergic to titanium or cobalt chromium alloys

Judged by surgeon to be too small in size for pedicle screw

placement

principles: limited posterior muscle dissection, lower implant density, semiconstrained instrumentation with more limited arthrodesis, and preservation of motion at instrumented segments adjacent to the curve apex. The 2-year clinical and radiographic results using these techniques and a description of the novel instrumentation is presented.

\section{MATERIALS AND METHODS}

\section{Study Design}

From April 2012 to January 2013, 21 patients were enrolled in a prospective, nonrandomized, multi-center, post-Conformité Européenne approved clinical pilot trial employing a novel posterior technique that utilizes translation and derotation principles combined with a short apical arthrodesis and longer instrumentation of unfused motion segments for surgical treatment of AIS. Four study centers (Czech Republic, United Kingdom, Slovakia, and Turkey) participated. The ethics committee of each institution approved the clinical trial. Additionally, Turkish Ministry of Health approval was obtained, and the study received portfolio adoption by the National Institute for Health Research Clinical Research Network in the United Kingdom. Prior to enrollment, written informed consent was obtained from each subject. Subjects were enrolled in the trial based on established inclusion and exclusion criteria (Table 1). An independent surgeon advisory board conducted clinical trial safety oversight. The postoperative, 6-month, 12-month, and 24-month outcomes as well as post-system removal outcomes are presented in this manuscript.

\section{Clinical Outcomes}

The presurgical patient health history, neurologic examination, rib prominence on forward bending, clinical photographs, and the Scoliosis Research Society 22r (SRS22r) questionnaire results were obtained for each subject.

\section{Radiographic Outcomes}

Preoperative standing posteroanterior (PA) and lateral, left/right lateral supine bending, and hand radiographs were obtained. The PA radiograph analysis included main thoracic curve Cobb angle, coronal balance (C7-central sacral vertical line) and clavicle angle (angle between horizontal reference line and superior margins of clavicles). Standing lateral radiographs were utilized for measuring thoracic kyphosis (Cobb angle T5-12), lumbar lordosis (Cobb angle L1-S1), and sagittal balance (C7-posterior superior corner of sacrum). Right and left side-bending supine radiographs assessed curve flexibility as well as motion of the segments that were instrumented but not fused. Vertebral rotation was assessed using a preoperative low-dose computed tomography (CT) scan of the thoracic curve apex (angle between the midsagittal line and the line connecting the vertebral centroid and posterior junction of the vertebral arch). An independent imaging core lab performed all radiographic analyses. Radiographic measurement utilized the validated Quantitative Motion Analysis software (Medical Metrics Inc., Houston, Texas). ${ }^{19-21}$

\section{Safety and Efficacy Outcomes}

The primary safety objective was avoidance of serious device- and/or procedure-related adverse events. The primary safety endpoint was measured by the percentage of patients who experienced one or more serious device- and/or procedure-related adverse events postoperatively. Secondary safety objectives included collecting the frequency and severity of all adverse events at time of procedure and over the follow-up period.

The primary efficacy objective was measured by the mean percentage of correction of the main thoracic curve at the postoperative assessments compared to preoperative assessments. A mean Cobb angle reduction of $50 \%$ was hypothesized. Secondary efficacy objectives included evaluation of patient outcomes utilizing the SRS22r questionnaire. Exploratory objectives included blood loss, operative time, length of hospital stay, sagittal and coronal alignment, kyphosis, lordosis, clavicle angle, rib prominence, and apical vertebral rotation. 


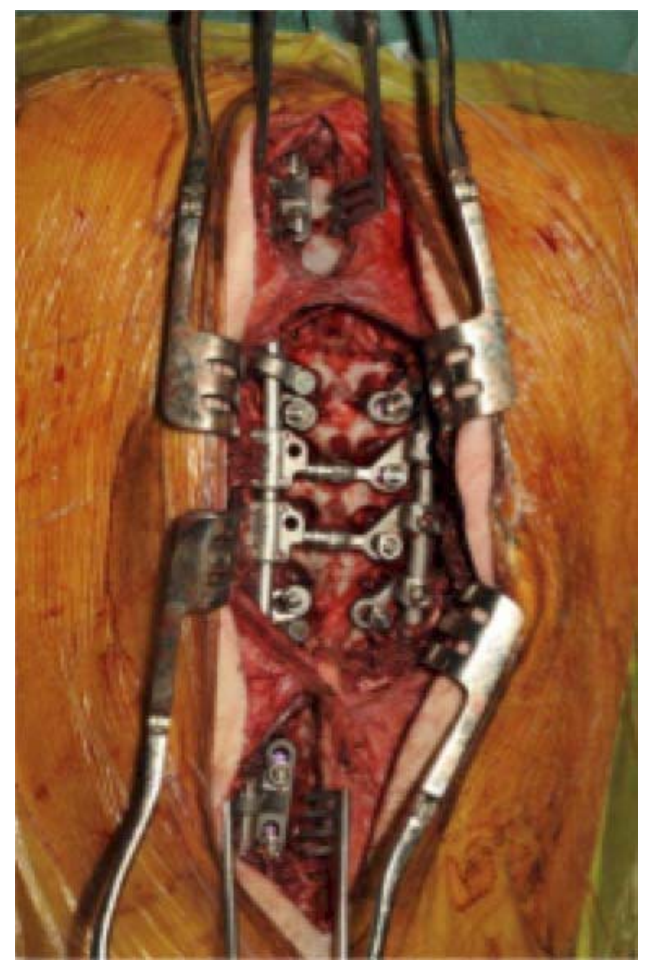

Figure 1. Depiction of 3-window surgical technique.

\section{Statistical Methods}

Device- and procedure-related adverse events were expressed as a percentage and reported along with the corresponding 2 -sided exact $95 \%$ binomial confidence interval. Power analysis for the main thoracic curve correction determined that a sample size of at least 13 patients was required to detect a $15 \%$ difference between the mean reduction of the main thoracic Cobb angle and the hypothesized population value of at least $50 \%$ reduction with $80 \%$ power and alpha of 0.05 using a 2 -sided 1sample Wilcoxon rank sum test. The mean, median, standard deviation, and minimum and maximum percentages of change were calculated. The significance of differences between the observed mean percentage of change and the hypothesized value of $50 \%$ reduction was evaluated using a 2-sided 1-sample Wilcoxon rank sum test, with $P$ $\leq .05$ being statistically significant. Differences between baseline and follow-up measurements of other variables were evaluated using a Wilcoxon matched pairs signed ranks test. Unless stated otherwise, 2-sided statistical tests were performed with alpha set at 0.05 . $P$ values $\leq .05$ indicate statistical significance.
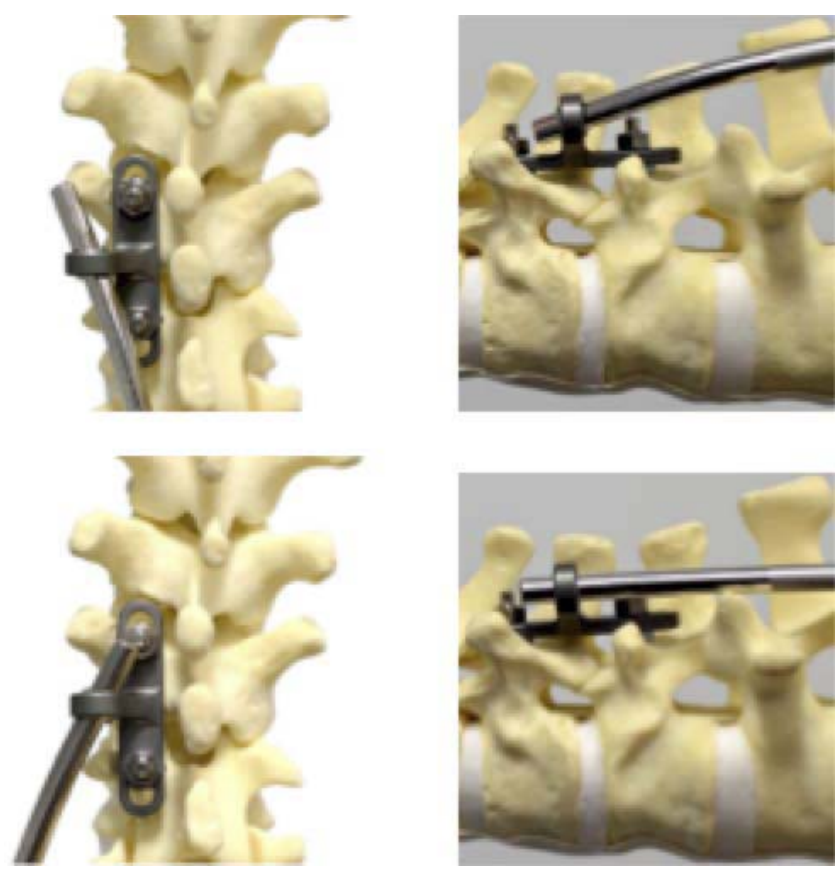

Figure 2. Mobile Heim anchors utilized at upper instrumented vertebra and lowest instrumented vertebra allow relative motion of the rod (eg, bending, flexion-extension, axial slide).

\section{Surgical Procedure}

Implantation was performed utilizing one midline skin incision from the upper instrumented vertebra (UIV) to the lowest instrumented vertebra (LIV) and 3 subfascial windows at the UIV, LIV, and apical region (ie, 3 to 5 vertebrae adjacent to curve apex) to minimize the amount of soft tissue disruption (Figure 1).

The system utilizes pedicle screws to anchor the instrumentation to the spine. The pedicles were prepared and screws implanted using the standard technique. The system is comprised of novel mechanically articulating Heim anchors implanted at the UIV and LIV and L-shaped transverse members implanted at the apical region. The articulating Heim anchors substantially block lateral translation while allowing angle and alignment changes to facilitate and control correction from the apex while retaining mobility at either end of the construct (Figure 2). The L-shaped fixation members traverse a vertebral body and avoid spanning motion segments vertically such that when a correction force is applied to the end of the Lshaped member, simultaneous translation and derotational forces are applied to the vertebrae (Figure 3).

Once the concave side rod was attached via the articulating Heim anchors and the L-shaped mem- 
a

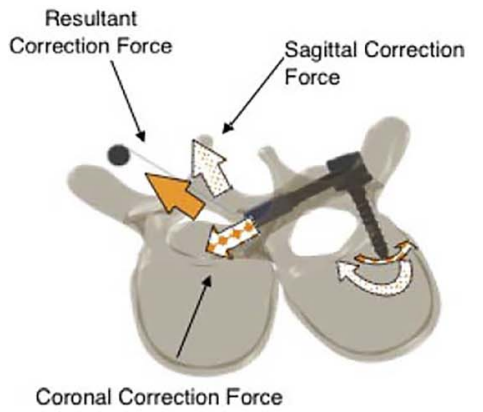

Coronal Correction Force
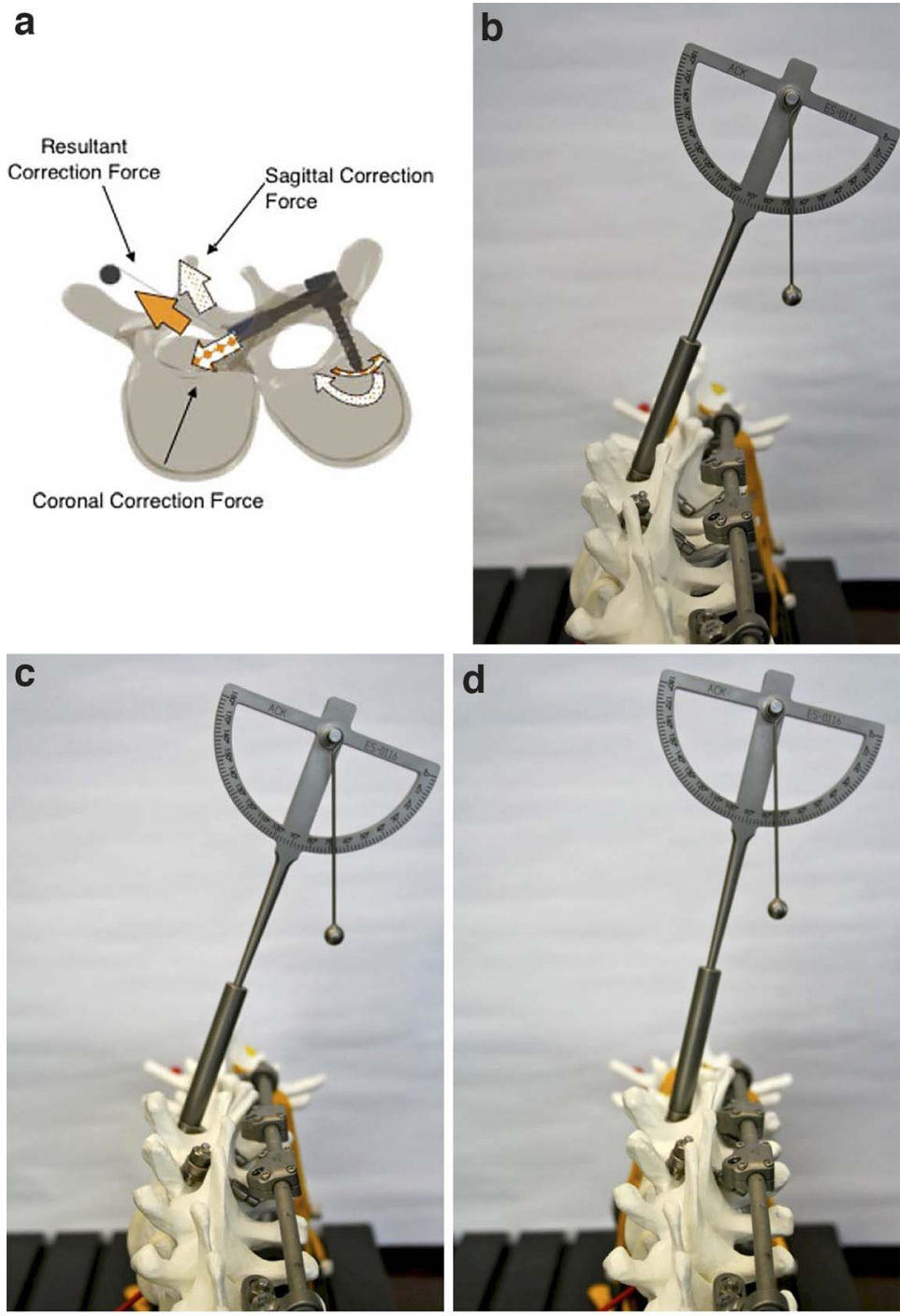

d

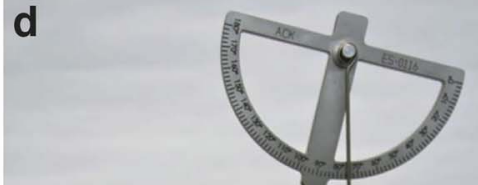

.

\section{e}

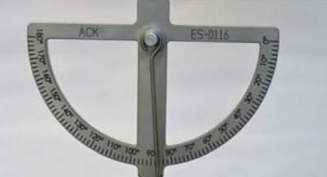

Figure 3. (a) Depiction of the deformity correction forces applied through L-shaped member. (b-e) Photographs showing axial correction during tightening of Lshaped member, done at initial surgery. 


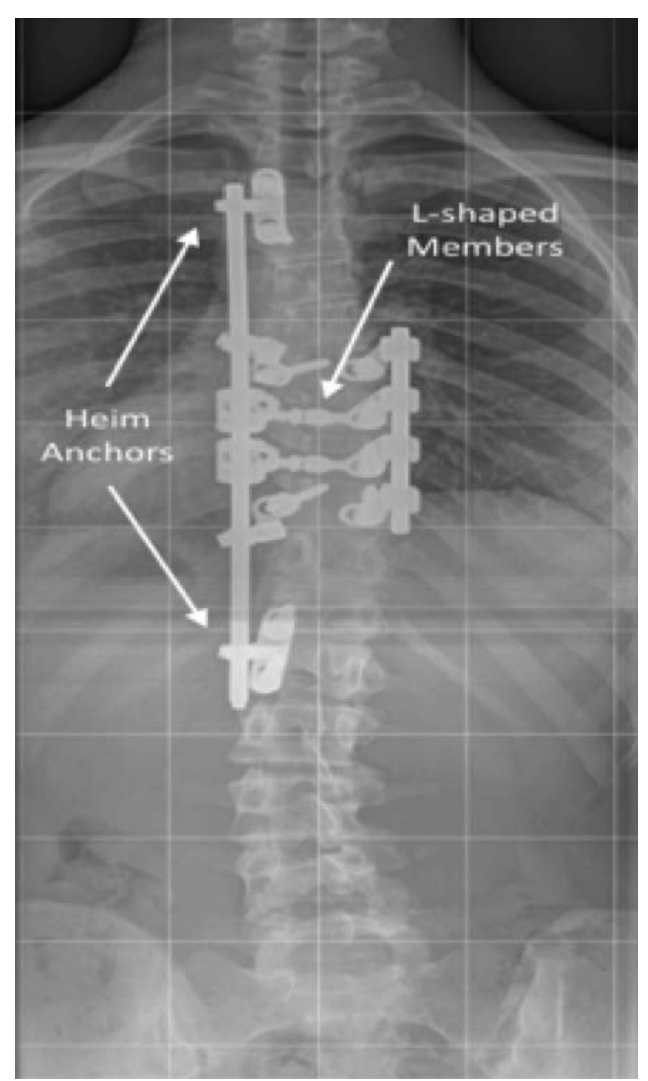

Figure 4. Radiograph image of typical postcorrection construct.

bers were secured to the convex apical pedicle screws, deformity correction was obtained by pulling the L-shaped members with a horizontal force toward the concave side rod. The L-shaped member has a wire that comes out horizontally and attaches to a wind-up component on the concave rod. The wire tightens in this apparatus and brings the vertebra over to the rod using both derotation and translation forces. After achieving visually improved alignment, the apical region was bilaterally stabilized with a short rod-screw construct connecting the screws on the convex side. The end result was bilateral rigid fixation of the apical segments, with only the concave side rod extending proximally and distally across nongrafted segments to the UIV and LIV (Figure 4). Local autograft was utilized for fusion of the immobilized apical motion segments with cortico-cancellous allograft filler as needed according to surgeon preference. The motion segments adjacent to the apical region were not prepared for fusion.

Patients were ambulatory without bracing the day following surgery. Activity restrictions after surgery varied with each site, with the general trend toward release to normal activities by 3 months
Table 2. Demographics $(n=21)$.

\begin{tabular}{lc}
\hline Characteristic & $\begin{array}{c}\text { Mean } \pm \text { SD (range) } \\
\text { or } \boldsymbol{n}(\%)\end{array}$ \\
\hline Lenke 1A & $20(95 \%)$ \\
Lenke 1B & $1(5 \%)$ \\
Female (\%) & $21(100 \%)$ \\
Sanders score & \\
$3-6$ & $14(67 \%)$ \\
$7-8$ & $7(33 \%)$ \\
Risser stage & \\
0 & $2(10 \%)$ \\
1 & $3(14 \%)$ \\
2 & $1(5 \%)$ \\
3 & $2(10 \%)$ \\
4 & $8(38 \%)$ \\
5 & $5(24 \%)$ \\
Previous treatment & \\
Bracing & $11(52 \%)$ \\
Bracing/physical therapy & $3(14 \%)$ \\
Physical therapy & $2(10 \%)$ \\
Observation/watchful waiting & $5(24 \%)$ \\
Age (years) & $14.2(11-17)$ \\
Height (cm) & $162.4(148-170)$ \\
Weight (kg) & $53.1(35-73)$ \\
BMI & $19.8(15-27)$ \\
Flexibility of thoracic curve $(\%)$ & $51.1(32-74)$ \\
Main thoracic Cobb angle $\left({ }^{\circ}\right)$ & $56.1(42-78)$ \\
$\%$ of patients that used analgesic medication & \\
Preoperatively & $5 / 21(24 \%)$ \\
2 weeks postoperatively & $12 / 21(57 \%)^{*}$ \\
3 months postoperatively & $3 / 21(14 \%)$ \\
6 months postoperatively & $3 / 21(14 \%)$ \\
12 months postoperatively & $4 / 21(19 \%)$ \\
\hline
\end{tabular}

*P value of 2 weeks postoperative compared with preoperative was .001 . The rest were $P>.05$.

postoperation. Patients were discouraged from participating in strenuous sports during the study period.

Surgical data collection included operative time, blood loss, levels fused, and levels instrumented. All device- and/or procedure-related adverse events were reported.

In this trial, it is hypothesized that motion of the instrumented but unfused segments will be maintained by virtue of the degrees of freedom afforded by UIV and LIV articulating Heim anchors at each end of the rod. By design, the articulating Heim anchors should allow axial compression, rotation, flexion-extension, and lateral bending of the instrumented but unfused segments. Thus, the system is postulated to be a load-sharing device that will make the spine the weakest stabilization link and not the implant itself.

\section{RESULTS}

\section{Demographics and Operative Outcomes}

The demographics for the 21 subjects in this trial are summarized in Table 2. Operative time averaged 
$258.0 \pm 56.3$ minutes (range: $158-410$ minutes) with blood loss of $933.3 \pm 429.9 \mathrm{~mL}$ (range: $300-2000$ $\mathrm{mL}$ ). Intraoperative blood transfusions, done at the discretion of anesthesiology, averaged 1.9 units (range: 1-4 units) of packed red blood cells per patient. Due to AIS surgical management routine protocol of the partaking centers, 19 out of 21 patients received blood transfusion intraoperatively. Postoperatively, 5 units of blood were transfused in 3 patients, each being reported as an adverse event since the transfusions were done after surgery. One of the 3 patients did not have any transfusions during the implant procedure. Intraoperative electrophysiological testing was stable in all monitored patients (19 patient), and there were no neurologic deficits at any point after surgery in the 21 patients. Hospital stay averaged $8.2 \pm 2.9$ days (range: 4 13days).

A mean of $11.3 \pm 1.8$ pedicle screws (range: 9-14 screws) were used per patient. The average number of pedicle screws per vertebra within the construct (screw density) was $0.97 \pm 0.15$ screws (range: $0.82-$ 1.27 screws/vertebra). The UIV levels varied: T2 (9 patients), T3 (9), T4 (3); LIV also varied: T11 (1 patient), T12 (3), L1 (7), L2 (8), and L3 (2). Independent CT assessment of all 238 screws placed showed 19 screws $(7.9 \%)$ had breached pedicle margins to some degree. None were symptomatic, though 1 screw $(0.4 \%)$ in 1 patient was removed due to a lateral position near the aorta.

The posterior arthrodesis averaged $5.0 \pm 0.5$ motion segments (range: 4-6), with an average of 10.5 motion segments instrumented per patient. Fusion was accomplished at 104 levels (47\% of instrumented levels), and 116 levels were instrumented without attempt at fusion.

\section{Clinical Outcomes}

There were no neurologic deficits, deep wound infections, medical complications, loosening of screws, failures of the implant components, or any other device-related complications. Analgesic use at 2 weeks postoperatively was increased over preoperative use $(P=.01)$, but improved compared to preoperative use at 3 months, 6 months, and 12 months postsurgery (Table 2).

The average SRS22r total scores in this trial were 3.7 (range: $1.9-4.5$ ) at baseline, 4.1 (range: $2.4-5.0$ ) at 6 months, 4.2 (range: 2.9-5.0) at 12 months, and 4.2 (range: 2.6-5.0) at 24 months. At 12 months postsurgery, $19 / 21$ patients $(91 \%)$ stated they were either very satisfied or satisfied and 2/21 noted they were neither satisfied nor unsatisfied. Patients were also asked if they would have the same procedure again, 19/21 patients (91\%) were definitely or probably sure they would have this treatment again, 2/21 were unsure.

\section{Radiographic Outcomes}

A representative series of anteroposterior (AP) standing radiographs is in Figure 5. The main thoracic Cobb angle and percentage of improvement in Cobb angle are summarized in Table 3. Overall, the instrumentation and correction methodology utilized in this trial were able to obtain and maintain a $62 \%$ improvement in the main thoracic Cobb angle.

The values for thoracic kyphosis, lumbar lordosis, sagittal balance, coronal balance, clavicle angle, rib prominence, and apical rotation are summarized in Table 4. Thoracic kyphosis (T5-T12) improved an average $7.6^{\circ}$ at 12 months and $8.8^{\circ}$ at 24 months compared to baseline with an average increase of $6.2^{\circ}$ and $7.3^{\circ}$ in lumbar lordosis. Changes in mean coronal and sagittal balance were not substantially different at any of the assessments. Clavicle angle was defined as the angle between the horizontal reference line (HRL) and the line connecting the superior margins of the left and right clavicles. A depressed right clavicle yields a positive angle, while a right clavicle above the HRL will give a negative angle. Clavicle angle changed $4.6^{\circ}$ at 12 months $\left(-0.8^{\circ}\right.$ preoperatively to $3.8^{\circ}$ at 12 months) and $2.8^{\circ}$ at 24 months $\left(-0.8^{\circ}\right.$ preoperatively to $2.0^{\circ}$ at 24 months). Mean rib prominence decreased 38\% $\left(16.7^{\circ}\right.$ versus $\left.10.4^{\circ}\right)$, the mean apical vertebral body rotation as measured on $\mathrm{CT}$ increased $2.5^{\circ}$ at 12 months compared with preoperative values, from $13.3^{\circ} \pm 5.8^{\circ}$ (range: $4^{\circ}-28^{\circ}$ ) to $15.8^{\circ} \pm 5.2^{\circ}$ (range: $\left.7^{\circ}-29^{\circ}\right)$.

In levels instrumented but not fused, motion measured based on the description of Hosseini et $\mathrm{al}^{1}$ was $26^{\circ}$ preoperatively compared to $10^{\circ}$ at 1 -year postsurgery demonstrating $38 \%$ maintenance of mobility in the nonfused segments.

\section{Implant Safety and Adverse Events}

There was one serious adverse event and 17 nonserious adverse events observed during the first 12 months. The serious adverse event required revision surgery for removal of an asymptomatic malpositioned pedicle screw identified on CT scan. 

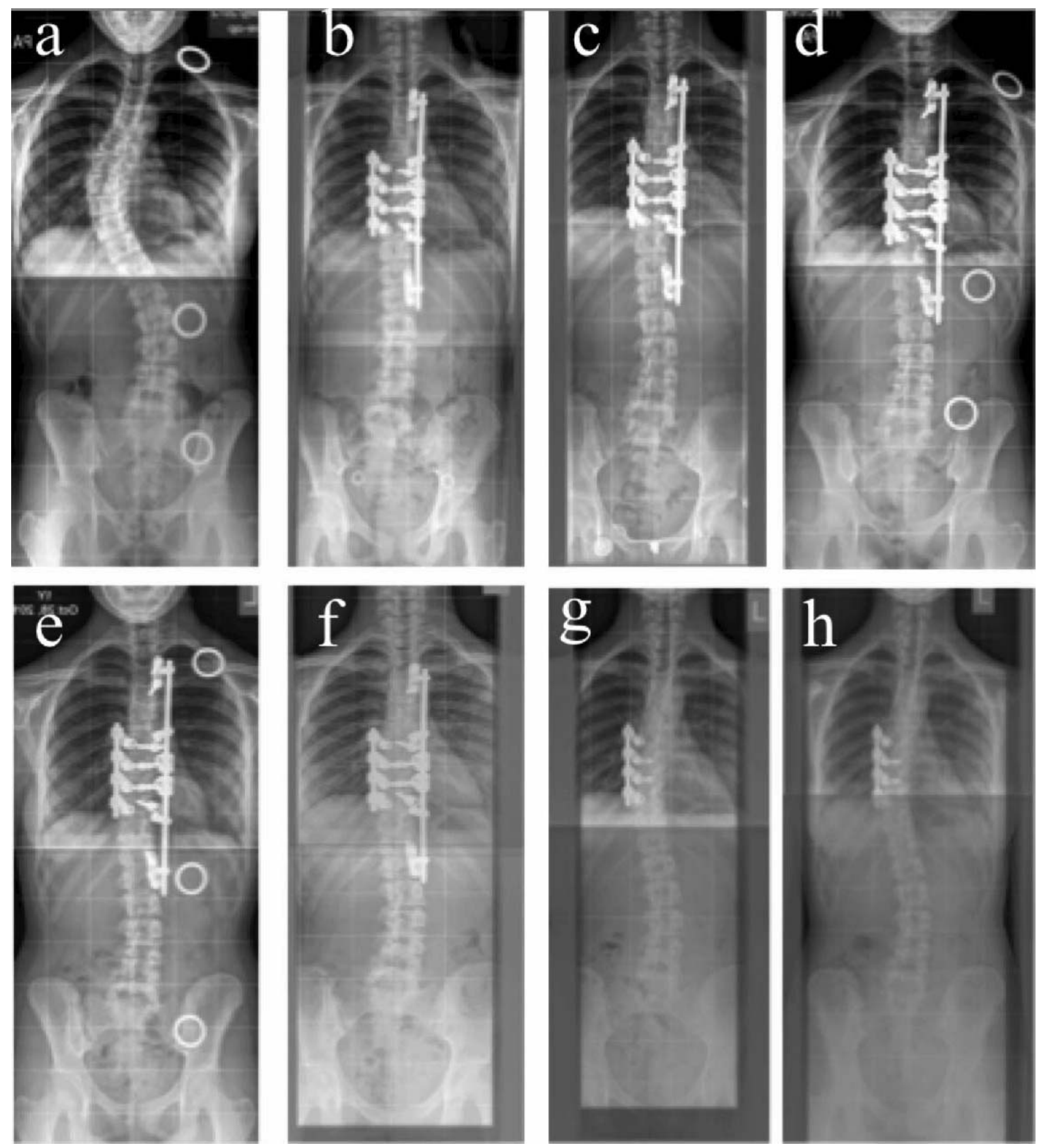

Figure 5. Standing AP radiographs. (a) preoperative, (b) postoperative, (c) 3 months postoperative, (d) 6 months postoperative, (e) 12 months postoperative, (f) 24 months postoperative, (g) 4 months postremoval, (h) 10 months postremoval.

There were no additional revision surgeries and there were no implant failures reported. Nonserious events included a single superficial wound infection and a urinary tract infection healed with antibiotics.
One patient had a scab remaining on the surgical incision at 3 months, which spontaneously resolved. Three patients developed postoperative anemia, which resolved after blood transfusion. One patient 


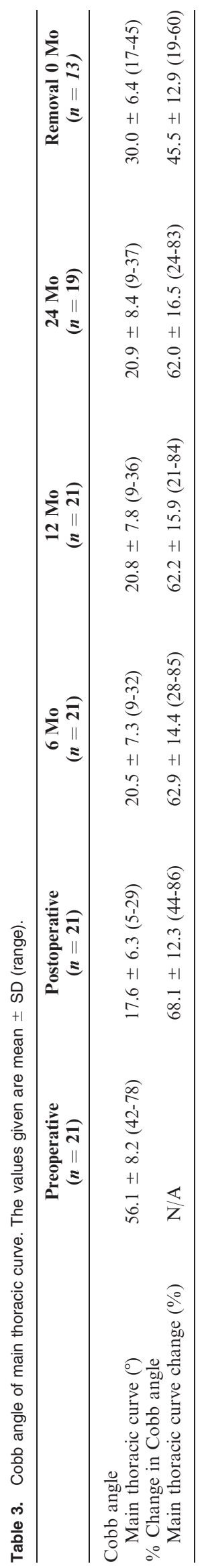

developed short-term self-resolving dizziness 6 months postoperatively for no identifiable reason. One patient developed a self-resolving back bruise after falling from a bike.

Nine of 21 patients reported back pain at some point during the 12 months follow-up. Minor pain began around 3 months post-operatively in 2 patients, associated with the ends of the construct, one of which resolved spontaneously. Two patients had nonfocal back pain before surgery and used analgesics. Both noted slightly worsened pain after surgery and continued using analgesics at a low or moderate frequency at 12 months. Temporary rib discomfort was described in one patient 4 months postoperatively, which resolved by 12 months. At 9 months postsurgery, 3 additional patients developed non-procedure/non-implant-related back pain after falling, after extensive coughing, and after being "kneed" in the back by a friend. At 12 months postsurgery, only the cough-related pain remained. Prior to surgery, 16/21(76\%) of patients described no pain. At 12 months, 17/21(81\%) were pain free.

\section{DISCUSSION}

Long-instrumented fusions have been the standard surgical treatment for AIS since the introduction of Harrington rods in the 1960s. ${ }^{22-24}$ Improved understanding of the forces acting on the deformi$t^{2,25}$ has led to refinements of correction strategies, fixation devices, and implant materials. ${ }^{4,7,26-33}$ More recently, the possibilities of shortening the required arthrodesis ${ }^{33-35}$ using less soft tissue dissection, ${ }^{16,36}$ and using fewer implants ${ }^{18,37-40}$ have been investigated in an effort to decrease fusion-related morbidity, ${ }^{13,14}$ retain maximum spinal motion, and decrease costs. ${ }^{17}$ The concept of dynamic segmental fixation to guide spinal growth without fusion has also been explored. ${ }^{41}$

This pilot trial prospectively evaluated a novel correction process and an improved spinal instrumentation system that utilized decreased soft and bony tissue dissection, lowered implant density, allowed apical derotation and translational deformity correction, and limited apical arthrodesis in AIS. Surgical correction was achieved using unique rod-screw connections, which facilitated derotational and translational correction of the apical vertebral bodies. The correction was maintained while allowing motion at the instrumented but unfused segments outside the apex, like the Shilla technique used in juvenile idiopathic scoliosis. ${ }^{42}$ 
Table 4. Sagittal, rotational, and balance measurements. The values given are mean \pm SD (range).

\begin{tabular}{|c|c|c|c|}
\hline & Preoperative & 12 Mo & 24 Мо \\
\hline Thoracic kyphosis: T5-T12 $\left(^{\circ}\right)$ & $15.9 \pm 8.0(2-26)$ & $23.5 \pm 7.4(14-43)$ & $24.7 \pm 6.9(14-39)$ \\
\hline$n$ & 21 & 21 & 18 \\
\hline$P$ & & .005 & .002 \\
\hline Lumbar lordosis: L1-S1 $\left(^{\circ}\right)$ & $57.6 \pm 13.0(38-82)$ & $63.8 \pm 9.6(46-82)$ & $64.9 \pm 7.9(54-85)$ \\
\hline$n$ & 20 & 20 & 18 \\
\hline$P$ & & .2 & .11 \\
\hline Sagittal balance $(\mathrm{cm})$ & $-2.3 \pm 3.8(-11$ to 4$)$ & $-2.7 \pm 2.6(-8$ to 1$)$ & $-2.7 \pm 2.2(-8$ to 1$)$ \\
\hline$n$ & 20 & 19 & 18 \\
\hline$P$ & & 1 & 1 \\
\hline Coronal balance $(\mathrm{cm})$ & $0.2 \pm 1.3(-3$ to 3$)$ & $-0.2 \pm 1.2(-2$ to 2$)$ & $-0.6 \pm 1.0(-3$ to 1$)$ \\
\hline$n$ & 21 & 21 & 18 \\
\hline$P$ & & .93 & .17 \\
\hline Clavicle angle $\left(^{\circ}\right)$ & $-0.8 \pm 2.5(-5$ to 3$)$ & $3.8 \pm 2.4(0$ to 9$)$ & $2.0 \pm 2.5(-1$ to 8$)$ \\
\hline$n$ & 18 & 21 & 18 \\
\hline$P$ & & $<.0001$ & .003 \\
\hline Rib prominence* $\left(^{\circ}\right)$ & $16.7 \pm 4.3(7-24)$ & $10.4 \pm 3.0(5-17)$ & $10.7 \pm 2.8(4-15)$ \\
\hline$n$ & 21 & 21 & 14 \\
\hline$P$ & & .05 & $<.05$ \\
\hline Apical rotation ${ }^{* *}\left({ }^{\circ}\right)$ & $13.3 \pm 5.8(4-28)$ & $15.8 \pm 5.2(7-29)$ & Not recorded \\
\hline$n$ & 21 & 21 & \\
\hline$P$ & & $<.05$ & \\
\hline
\end{tabular}

* Rib prominence measured with scoliometer.

**Apical rotation measured with computed tomography

Though not a true minimally invasive surgery (MIS) ${ }^{36}$ subperiosteal dissection for these patients was limited only to the apical motion segments, UIV, and LIV intended for fusion. Also, unlike MIS techniques, all pedicle screws were placed under direct landmark visualization without the need for extensive fluoroscopy. Since the technique described here keeps half of the motion segments beneath the instrumentation unfused and mobile, the option of removal of the instrumented but unfused levels after maturation is encouraged. Regarding the indication for implant removal in this new technique, it is important to mention that at the time of current study the regulations climate was not in favor of leaving any implant in situ without fusion at skeletal maturity. In addition, at the time of the study, the authors believed that leaving implants in without fusion would both decrease range of motion of spine and increase the possibility of implant failure, which both will be reflected in results of the new system. Longer-term results will certainly answer whether implant removal at skeletal maturity will improve the results or not.

The only procedure-related adverse event was the single malpositioned pedicle screw, which required revision. There were no associated sequelae with the removal surgery, and deformity correction minimally worsened. The 17 nonserious adverse events that were noted during 12 months of follow-up reflected the investigators' close patient scrutiny to include even minor and unrelated back complaints not normally reported as complications. It was also noted that blood loss and hospital stay were longer than expected, which might be due to the learning curve that occurs in any new technique. In addition, in this study PASS was performed in different centers in 4 different countries. Longer hospital stays can be attributed to different hospital stay protocols. The blood loss issue was a determinant decided by each center and they attempted to keep blood count above a level that was more numeric than symptomatic; anesthetic control techniques may also have varied between centers.

The primary efficacy objective was the correction of the main thoracic curve compared to baseline. Curve correction in this series $(62.2 \%$ at 12 months and $62.0 \%$ at 24 months postsurgery) was similar to the deformity correction achieved using standard surgical techniques, ${ }^{12,42-45}$ but was achieved while limiting fusion at 4 to 6 levels; arthrodesis of 9 to 12 levels is common with standard AIS surgery. As it is shown in Table 4, there were changes in coronal balance, sagittal balance, and spinal height (T1-S1 height). However, as is supported by $P$ values, these changes are not statistically significant $(P>.05)$. In addition, postoperative thoracic hypokyphosis as reported by others ${ }^{43,46-50}$ was not noted in this clinical trial. Thoracic kyphosis in this clinical trial increased an average $7.6^{\circ}$ at 12 months and $8.8^{\circ}$ at 24 months with the described technique.

A secondary efficacy objective was the difference in domains in the SRS22 ${ }^{51,52}$ questionnaire from 
baseline. In the evaluation of scoliosis the SRS22r is a disease-specific instrument to assess health-related quality of life. It is composed of function, pain, selfimage, mental health, and satisfaction. The average score of these 5 components showed improvement in this study, which was in line with what others have noted. ${ }^{8}$

The data reported in this clinical trial are sufficient to address safety and efficacy through the first 24 months and immediately following system removal. Future study is needed to monitor deformity correction stability as well as to compare spinal column motion of the instrumented but unfused segments compared to the motion of these segments after the long stabilizing rod is removed.

In the big picture, this concept of correction may be advanced to allow for apical correction, curve stabilization, and removal of implants at maturation in AIS patients as the system allows for more biomechanical freedom when implants are in place. This is accomplished by having horizontal implant capture and connection at several points compared to the present-day vertical segmental fixation methods spanning multiple levels. The technique reported is designed to allow more freedom for potential structural remodeling of bone and soft tissue (disc) that could lead to correction, stabilization, and greater maintenance of spinal mobility. In the future, it may be found that deformity correction with changes in load sharing and continued spinal motion may lead to bone and soft tissue remodeling and force redistribution of imposed alignment. This may mimic a limb-growth stapling procedure or the Ilizarov deformity correction methodology.

\section{CONCLUSION}

Safety and efficacy outcomes data over 24 months suggests this novel posterior technique for the treatment of AIS achieved similar deformity correction as standard surgical techniques but required fewer surgical implants and a shorter arthrodesis. Quality-of-life total scores as measured by SRS22r were improved at 6, 12, and 24 months compared to baseline. There was one device/ procedure-related adverse event (asymptomatic malpositioned pedicle screw) that required revision as a safeguard. The results of this clinical trial through 24 months present a safe and effective new posterior technique for the treatment of AIS that has great potential to enhance and evolve the biomechanical solutions presently available for treating AIS.

\section{REFERENCES}

1. Hosseini P, Nnadi C, Rehák L, Repko M, Grevitt M, Aydinli U, Carl A, Pawelek J, Crandall D, Akbarnia BA. Analysis of segmental mobility following a novel posterior apical short-segment correction for adolescent idiopathic scoliosis. Spine (Phila Pa 1976). 2016;41(20):E1223-E1229. https://doi.org/10.1097/BRS.0000000000001607F

2. Wang $\mathrm{X}$, Aubin $\mathrm{CE}$, Labelle $\mathrm{H}$, et al. Biomechanical analysis of corrective forces in spinal instrumentation for scoliosis treatment. Spine (Phila Pa 1976). 2012;37(24):E1479E1487.

3. Wang X, Aubin CE, Crandall DG. Biomechanical comparison of force levels in spinal instrumentation using monoaxial versus multidegree of freedom postloading pedicle screws. Spine (Phila Pa 1976). 2011;36(2):E95-E104.

4. Wang X, Aubin CE, Crandall DG. Biomechanical analysis of 4 types of pedicle screws for scoliotic spine instrumentation. Spine (Phila Pa 1976). 2012;37(14):E823E835.

5. Cho KJ, Suk S, Park SR, et al. Selection of proximal fusion level for adult degenerative lumbar scoliosis. Eur Spine J. 2013;22(2):394-401.

6. Engsberg J, Lenke L, Reitenback A, Hollander K, Bridwell K, Blanke K. Prospective evaluation of trunk range of motion in adolescents with idiopathic scoliosis undergoing spinal fusion surgery. Spine (Phila Pa 1976). 2002;27(12):13461354.

7. Rushton PR, Grevitt MP. Do vertebral derotation techniques offer better outcomes compared to traditional methods in the surgical treatment of adolescent idiopathic scoliosis? Eur Spine J. 2014;23(6):1166-1176.

8. Rushton PR, Grevitt MP. What is the effect of surgery on the quality of life of the adolescent with adolescent idiopathic scoliosis? A review and statistical analysis of the literature. Spine (Phila Pa 1976). 2013;38(9):786-794.

9. Malfair D, Flemming A, Dvorak M, Munk P, Vertinsky A, Hera M, Graeb D. Radiographic evaluation of scoliosis: review. AJR Integrative Imaging. 2010;194(3 Suppl):S8-S22.

10. Behensky H, Cole AA, Freeman BJC, Grewit MP, Mehdina HS, Webb JK. Fixed lumbar apical vertebral rotation predicts spinal decompensation in Lenke type $3 \mathrm{c}$ adolescent idiopathic scoliosis after selective posterior thoracic correction and fusion. Eur Spine J. 2007;16(10):1570-1578.

11. Lenke LG, Betz RR, Bridwell KH, et al. Inter-observer and intra-observer reliability of the classification of thoracic adolescent idiopathic scoliosis. J Bone Joint Surg Am. 1998;80A:1097-1106.

12. Newton PO, Marks MC, Bastrom TP, et al. Surgical treatment of Lenke 1 main thoracic idiopathic scoliosis: results of prospective, multicenter study. Spine (Phila Pa 1976). 2013;38(4):328-338.

13. Cuartas E, Rasouli A, O’Brien M, Shufflebarger HL. Use of all-pedicle-screw constructs in the treatment of adolescent idiopathic scoliosis. J Am Acad Orthop Surg. 2009;17(9):550-561.

14. Harding J, Charosky S, Vialle R, Chopin DH. Lumbar 
disc degeneration below a long arthrodesis performed for scoliosis in adults) to L4 or L5. Eur Spine J. 2008;17(2):250254.

15. Marks M, Newton P, Petcharaporn M, Bastrom T, Shah S, Betz R, Lonner B, Miyanji F. Postoperative segmental motion of the unfused spine distal to the fusion in 100 patients with adolescent idiopathic scoliosis. Spine (Phila Pa 1976). 2013;37(10):826-832.

16. Hansen-Algenstaedt N, Schafer C, Beyerlein J, Wiesner L. Percutaneous scoliosis surgery. Eur Spine J. 2012;21(6):12251227.

17. Martin CT, Pugely AJ, Gao Y, Mendoza-Lattes SA, Ilgenfritz RM, Callaghan JJ, Weinstein SL. Increasing hospital charges for adolescent idiopathic scoliosis in the United States. Spine (Phila Pa 1976). 2014;39(20):1676-1682.

18. Larson AN, Polly DW Jr, Diamond B, Ledonio C, Richards BS 3rd, Emans JB, Sucato DJ, Johnston CE. Minimize Implants Maximize Outcomes Study Group. Does higher anchor density result in increased curve correction and improved clinical outcomes in adolescent idiopathic scoliosis? Spine (Phila Pa 1976). 2014;39(7):571-578.

19. Zhao KD, Yang C, Zhao C, Stans AA, An KN. Assessment of noninvasive interbertebral motion measurements in the lumbar spine. J Biomech. 2005;38(9):1943-1946.

20. Pearson AM, Spratt KF, Genuario J, McGough W, Kosman K, Lurie J, Sengupta DK. Precision of lumbar intervertebral measurements: does a computer-assisted technique improve reliability? Spine. 2011;36(7):572-580.

21. Auerbach J, Namdari S, Milby A, White A, Reddy S, Lonner B, Balderston R. The parallax effect in the evaluation of range of motion in lumbar total disc replacement. SAS J. 2008;2(4):184-188.

22. Harrington PR. Surgical instrumentation for management of scoliosis. J Bone Joint Surg. 1960;42:1448.

23. Harrington PR. The history and development of Harrington instrumentation. Clin Orthop Relat Res. 1973;93:110-112.

24. Lonstein J. Adolescent idiopathic scoliosis. The Lancet. 1994;344(8934):1407-1412.

25. Robitaille M, Aubin CE, Labelle H. Biomechanical assessment of variable instrumentation strategies in adolescent idiopathic scoliosis: preliminary analysis of 3 patients and 6 scenarios. Stud Health Technol Inform. 2006;123:309-314.

26. King HA, Moe JH, Bradford DS, Winter RB. Selection of fusion levels in thoracic idiopathic scoliosis. J Bone Joint Surg. 1983;65(9):1302-1314.

27. Cotrel Y, Dubousset J, Guillaumat M. New universal instrumentation in spinal surgery. Clin Orthop Rel Res. 1988;227:10-23.

28. Boachie-Adjei O, Bradford DS. Vertebral column resection and arthrodesis for complex spinal deformities. $J$ Spinal Disord. 1991;4(2):193-202.

29. Hwang SW, Samdani AF, Marks M, et al. Five-year clinical and radiographic outcomes using pedicle screw only constructs in the treatment of adolescent idiopathic scoliosis. Eur Spine J. 2013;22(6):1292-1299.

30. Serhan H, Mhatre D, Newton P, Giorgio P, Sturm P. Would $\mathrm{CoCr}$ rods provide better correctional forces than stainless steel or titanium for rigid scoliosis curves? J Spinal Disord Tech. 2013;26(2):E70-E74.

31. Mattila M, Jalanko T, Helenius I. En bloc vertebral column derotation provides spinal derotation but no additional effect on thoracic rib hump correction as compared with no derotation in adolescents undergoing surgery for idiopathic scoliosis with total pedicle screw instrumentation. Spine (Phila Pa 1976). 2013;38(18):1576-1583.

32. Martino J, Aubin CE, Labelle H, Wang X, Parent S. Biomechanical analysis of vertebral derotation techniques for the surgical correction of thoracic scoliosis. A numerical study through case simulations and a sensitivity analysis. Spine (Phila Pa 1976). 2013;38(2):E73-E83.

33. Di Silvestre M, Lolli F, Bakaloudis G, Maredi E, Vommaro F, Pastorelli F. Apical vertebral derotation in the posterior treatment of adolescent idiopathic scoliosis: myth or reality? Eur Spine J. 2013;22(2):313-323.

34. Chang KW, Chen YY, Leng X, Wu CM, Chen TC, Wang YF, Zhang GZ. Guan-Din method: a novel surgical technique for selective thoracic fusion to maximize the rate of selective thoracic fusion and compensatory correction. Spine (Phila Pa 1976). 2014;39(4):E284-E93.

35. McCarthy RE, Luhmann S, Lenke L, McCullough FL. The Shilla growth guidance technique for early-onset spinal deformities at 2-year follow-up: a preliminary report. $J$ Pediatr Orthop. 2014;34(1):1-7.

36. Sarwahi V, Horn JJ, Kulkarni PM, Wollowick AL, Lo Y, Gambassi M, Amaral TD. Minimally invasive surgery in patients with adolescent idiopathic scoliosis: is it better than the standard approach? A two-year follow-up study. Clin Spine Surg. 2016;29(8):331-340.

37. Sanders JO, Diab M, Richards SB, et al. Fixation points within the main thoracic curve: does more instrumentation produce greater curve correction and improved results? Spine (Phila Pa). 2011;36(21):E1402-1406.

38. Yang S, Jones-Quaidoo SM, Eager M, et al. Right adolescent idiopathic thoracic curve (Lenke $1 \mathrm{~A}$ and B): does cost of instrumentation and implant density improve radiographic and cosmetic parameters? Eur Spine J. 2011;20(7):10391047.

39. Li J, Cheung KM, Samartzis D, Ganal-Antonio AK, Zhu X, Li M, Luk KD. Key-vertebral screws strategy for main thoracic curve correction in patients with adolescent idiopathic scoliosis. Clin Spine Surg. 2016;29(8):E434-E441.

40. Liu T, Hai Y. Sagittal plane analysis of selective posterior thoracic spinal fusion in adolescent idiopathic scoliosis: a comparison study of all pedicle screw and hybrid instrumentation. J Spinal Disord Tech. 2014;27(5):277-282.

41. Rehak L. A device for the dynamic correction and stabilization of spinal deformities. In: Brock M, Schwarz W, Wille C, eds. First Interdisciplinary World Congress on Spinal Surgery 2000. Bologna, Italy: Monduzzi Editore, International Proceedings Division; 2000: 623-627.

42. McCarthy RE, McCullough FL. Shilla growth guidance for early-onset scoliosis: results after a minimum of five years of follow-up. J Bone Joint Surg Am. 2015;97(19):1578-1584.

43. Luk KD, Lu DS, Cheung KM, et al. A prospective comparison of the coronal deformity correction in thoracic scoliosis using four different instrumentations and the fulcrumbending radiograph. Spine (Phila Pa 1976). 2004;29(5):560563.

44. Delorme S, Labelle $\mathrm{H}$, Aubin CE. Intraoperative comparison of two instrumentation techniques for the correc- 
tion of adolescent idiopathic scoliosis: rod rotation and translation. Spine (Phila Pa 1976). 1999;24(19):2011-2017.

45. Girardi FP, Boachie-Adjei O, Burke SW, et al. Surgical treatment of adolescent idiopathic scoliosis: a comparative study of two segmental instrumentation systems. $J$ Spinal Disord. 2001;14(1): 46-53.

46. Kim YJ, Lenke LG, Kim J, et al. Comparative analysis of pedicle crew versus hybrid instrumentation in posterior spinal fusion of adolescent idiopathic scoliosis. Spine (Phila Pa 1976). 2006;31(3):291-298.

47. Cao Y, Xiong W, Li F. Pedicle screw versus hybrid construct instrumentation in adolescent idiopathic scoliosis: meta-analysis of thoracic kyphosis. Spine (Phila Pa 1976). 2014;39(13):E800-E810.

48. Rhee JM, Bridwell KH, Won DS, et al. Sagittal plane analysis of adolescent idiopathic scoliosis: the effect of anterior versus posterior instrumentation. Spine (Phila Pa 1976). 2002;27(21):2350-2356.

49. Lowenstein JE, Matsumoto H, Vitale MG, et al. Coronal and sagittal plane correction in adolescent idiopathic scoliosis: a comparison between all pedicle screw versus hybrid thoracic hook lumbar screw constructs. Spine (Phila Pa 1976). 2007;32(4):448-452.

50. Sucato DJ, Agrawal S, O'Brien MF, et al. Restoration of thoracic kyphosis after operative treatment of adolescent idiopathic scoliosis: a multicenter comparison of three surgical approaches. Spine (Phila Pa 1976). 2008;33(24):2630-2636.

51. Glattes RC, Burton DC, Lai SM, et al. The reliability and concurrent validity of the Scoliosis Research Society-22r patient questionnaire compared with the Child Health Questionnaire-CF87 patient questionnaire for adolescent spinal deformity. Spine (Phila Pa 1976). 2007;32(16):1778-1784.

52. Merola AA, Haher TR, Brkaric M, et al. A multicenter study of the outcomes of the surgical treatment of adolescent idiopathic scoliosis using the Scoliosis Research Society (SRS) outcome instrument. Spine (Phila Pa 1976). 2002;27(18):20462051.

Disclosures and COI: K-Spine Inc. funded this study from 2012-14 prior to being acquired by K2M in 2015. L. Rehák received grants/research support from DePuy Synthes Spine and Kspine. M. Repko received grants/research support from Kspine. M. Grevitt received grants/research support from DePuy Synthes Spine and Medtronic and acted as a consultant for DePuy Synthes Spine.
U. Aydinli received grants/research support from Kspine. A. Carl served on an advisory board or panel for $\mathrm{K} 2 \mathrm{M}$ and Kspine and acted as a consultant and received other financial or material support (royalties, patents, stock options, etc.) from Kspine. C. Nnadi has no conflicts. B.A. Akbarnia was a stock or shareholder for Alphatec and Nuvasive; received grants/research support from DePuy Synthes Spine and Nuvasive; was a consultant for Ellipse Technology, K2M, and Kspine; served on an advisory board or panel for Kspine; and received other financial or material support (royalties, patents, stock options, etc.) from Kspine, Nuvasive, K2M, Ellipse Technology, and Depuy Synthes Spine. D. Crandall was a consultant for Ellipse Technology, Kspine, Medtronic, Spinewave, Stryker, and Zyga; served on an advisory board or panel for Kspine and on a speaker's bureau for Stryker; and received other financial or material support (royalties, patents, stock options, etc.) from Kspine and Medtronic. For the rest of coauthors nothing was disclosed. This study was Institutional Review Board-approved at each participating institution prior to initiation. The medical device stated in this manuscript is not cleared by US Food and Drug Administration.

Corresponding Author: Pooria Hosseini, MD., MSc., San Diego Spine Foundation, 6190 Cornerstone Ct., Ste 212, San Diego, CA 92121. Phone: (858) 246-6305; Email: phosseini@ sandiegospinefoundation.org.

Published 31 August 2018

This manuscript is generously published free of charge by ISASS, the International Society for the Advancement of Spine Surgery. Copyright (c) 2018 ISASS. To see more or order reprints or permissions, see http://ijssurgery.com. 